\title{
PENGARUH KREDIT PERBANKAN TERHADAP \\ PERTUMBUHAN INDUSTRI MANUFAKTUR DALAM MENUNJANG PERTUMBUHAN EKONOMI INDONESIA
}

\author{
Oleh: \\ Zulfita Fithriyah \\ Alumni Fakultas Ekonomi Universitas Muhammadiyah Malang \\ Nazaruddin Malik \\ Fakultas Ekonomi Universitas Muhammadiyah Malang \\ E-mail/No. Hp: nazarmf.malik@gmail.com/08123302313
}

\begin{abstract}
This research works through about influence between banking credit insuranceansies with industrial growth of manufacture. Besides also studies about vesting influence of credit insuranceansi to economic growth in Indonesia. Based on research done, obtained result that level of credit insuranceansi given to manufacture industry will affect at improvement of output at company. So equally, the many vestings of credit insuranceansi compares linear with industrial improvement of manufacture. At research hereinafter, happened the relation of concurrent between industrial growths of manufacture with chartered investment counsel growth. Where when industrial growth of manufacture increased hence will cause improvement at chartered investment counsel growth. Manufacture industry is one of economic sector, which if manufacture industry increased hence its the contribution is ever greater to chartered investment counsel growth. So growth of chartered investment counsel can increase.
\end{abstract}

Keywords: industrial growth of manufacture, economic of Indonesia

\section{PENDAHULUAN}

Dalam masa pembangunan nasional seperti sekarang ini, dimasa pemerintah menekankan pada unsur pemerataan yang akan menuju pada suatu pertumbuhan yang meningkat, maka kegiatan usaha khususnya di bidang ekonomi haruslah dapat menunjang hal tersebut karena bidang ekonomi inilah salah satu unsur penting yang akan dijadikan barometer keberhasilan kebijaksanaan pemerintah.

Menurut Sutojo (1995:2) untuk kegiatan penyediaan kredit, bank menerima balas jasa berupa bunga kredit. Selisih antara bunga kredit yang diterima dari debitur dengan bunga deposito, bunga pinjaman antar bank dan jasa giro yang mereka bayarkan kepada para penitip dana merupakan salah satu sumber pendapatan bank umum yang terbesar. Untuk memperlancar operasinya, bank mendirikan cabang didaerah-daerah dengan tujuan memberikan pelayanan kredit perbankan kepada masyarakat terutama pada industri manufaktur.

Berdasarkan data diatas dapat disimpulkan bahwa pengajuan kredit pada sektor ekonomi perindustrian (manufacturing) mengalami peningkatan dari tahun ke tahun yakni dari tahun 2003 sampai 2008. Hal ini sudah dikatakan maju karena ciri daripada negara yang berkembang adalah semakin meningkatnya laju pertumbuhan sektor 
industri. Dengan meningkatnya laju pertumbuhan industri manufaktur akan berpengaruh pula terhadap pertumbuhan ekonomi.

Berdasarkan hal tersebut, maka penelitian ini bertujuan untuk mengetahui perkembangan kredit perbankan, pertumbuhan industri manufaktur dan pertumbuhan ekonomi, mengetahui besarnya pengaruh kredit perbankan terhadap pertumbuhan industri manufaktur, mengetahui ada tidaknya pengaruh signifikan antara pertumbuhan industri manufaktur terhadap pertumbuhan ekonomi, serta mengetahui realisasi pengaruh kredit perbankan terhadap pertumbuhan ekonomi.

\section{TINJAUAN PUSTAKA}

Industri Pengolahan/Manufak-tur adalah semua kegiatan ekonomi yang menghasilkan barang dan jasa yang bukan tergolong produk primer. Yang dimaksudkan dengan produk primer adalah produk-produk yang tergolong bahan mentah. Dihasilkan oleh kegiatan eksploitasi sumber daya alam hasil pertanian, kehutanan, kelautan dan pertambangan dengan kemungkinan mencakup produk pengolahan-awal sampai dengan bentuk dan spesifikasi teknis yang standar dan lazim diperdagangkan sebagai produk primer.

Menurut Sutojo (1995:49), Dalam pemberian kredit perbankan oleh pemerintah melalui bank atau lembagalembaga keuangan ini biasanya tidak hanya sebatas pada pemberian pinjaman dalam bentuk modal, tetapi juga pembinaan manajemen. Sehingga dalam hal ini industri manufaktur yang memperoleh kredit akan mudah untuk dipantau tingkat perkembangan usahanya. Sebab ada beberapa perusahaan yang telah mengambil kredit akan tetapi sulit dalam operasionalnya dan bahkan terdapat adanya kredit macet, hal ini karena manajemen perusahaan tersebut tidak berjalan semestinya.

Menurut Boediono (1988:2), ada banyak faktor yang menentukan output per kapita dalam jangka panjang. Salah satunya ialah modal. Apabila perusahaan tersebut mengalami krisis modal, maka perusahaan industri manufaktur dapat mengajukan kredit untuk menutupi krisis modal yang dialaminya. Dengan adanya pinjaman kredit, maka perusahaan industri dapat memiliki modal yang mereka butuhkan.

\section{METODE PENELITIAN}

Metode penelitian ini digunakan untuk membuktikan dua hipotesis yang diajukan, yaitu: (1) diduga kredit perbankan berdampak pada pertumbuhan industri manufaktur, (2) diduga pertumbuhan industri manufaktur berdampak terhadap pertumbuhan ekonomi, serta (3) diduga kredit perbankan berdampak terhadap pertumbuhan ekonomi.

Adapun variabel yang digunakan dalam penelitian ini meliputi : (1) Variabel independent meliputi Kredit Perbankan (X), (2) Variabel Dependent, terdiri dari Pertumbuhan industri manufaktur $\left(\mathrm{Y}_{1}\right)$ dan Pertumbuhan Ekonomi $\left(\mathrm{Y}_{2}\right)$. Sehingga terdapay dua tahap dalam uji regresi.

Uji regresi linier yang pertama digunakan untuk menghitung serta mengetahui hubungan antara Pertumbuhan Industri Manufaktur $\left(\mathrm{Y}_{1}\right)$ dengan Kredit Perbankan (X), rumus yang akan digunakan sebagai berikut :

$$
\mathrm{Y}_{1}=\mathrm{a}+\mathrm{bX}+\mathrm{e}
$$

Dimana: $\quad Y_{1}=$ Pertumbuhan Industri Manufaktur (\%); a = Harga $\mathrm{Y}$ bila $\mathrm{X}=0$ ( Harga Konstan ); $\mathrm{b}=$ Angka arah atau koefesien regresi; $\mathrm{X}=$ Jumlah 
Kredit yang diberikan pada industri manufaktur (Miliar Rupiah); e = Standart kesalahan.

Uji regresi selanjutnya yakni menghitung dan mengetahui dampak antara Pertumbuhan industri manufaktur $\left(\mathrm{Y}_{1}\right)$ terhadap pertumbuhan ekonomi $\left(\mathrm{Y}_{2}\right)$, rumus yang akan digunakan sebagai berikut:

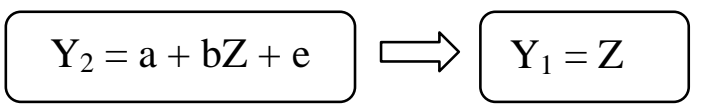

Dimana: $\mathrm{Y}_{2}=$ Pertumbuhan Ekonomi (\%); a = Harga $\mathrm{Y}$ bila $\mathrm{Z}=$ 0 ( Harga Konstan ); b = Angka arah atau koefesien regresi; $\mathrm{Z}=$ Pertumbuhan industri manufaktur (\%); e = Standart kesalahan.

Pengaruh kredit perbankan (X) terhadap pertumbuhan ekonomi $\left(\mathrm{Y}_{2}\right)$ digunakan rumus sebagai berikut :

$$
\mathrm{Y}_{2}=\mathrm{a}+\mathrm{bX}+\mathrm{e}
$$

Dimana: $\mathrm{Y}_{2}=$ Pertumbuhan ekonomi $(\%) ; \mathrm{a}=$ Harga $\mathrm{Y}$ bila $\mathrm{X}=0$ ( Harga Konstan); $\mathrm{b}=$ Angka arah atau koefesien regresi; $\mathrm{X}=$ Kredit yang diberikan pada industri manufaktur (miliar rupiah); e = Standart kesalahan.

Adapun untuk menguji hipotesis ini digunakan uji $t$ dan uji F.

\section{PEMBAHASAN}

Angka pertumbuhan kredit perbankan pada sektor industri manufaktur (Gambar 1) dari tahun 20042008 perubahannya bersifat fluktuatif. Kredit perbankan yang diberikan oleh bank-bank umum pada sektor industri manufaktur setiap tahunnya mengalami peningkatan yakni dari tahun 2003 sebesar 123.810 dan angka pertumbuhan yang diperoleh pada tahun 2004 sebesar 21.107. Hal ini disebabkan karena adanya peningkatan kredit yang dipinjam oleh industri manufaktur.

Pertumbuhan industri manufaktur dari tahun ke tahun mengalami peningkatan (Gambar 2) seperti halnya pada tahun 2005 pertumbuhan industri manufaktur mencapai rata-rata sebesar 119,14 dan angka pertumbuhannya sebesar 1,80 namun pada tahun berikutnya yakni 2006 pertumbuhan industri manufaktur mencapai penurunan rata-rata sebesar 116,92 sehingga angka pertumbuhan sebesar -2,22. Walaupun pada kenyataannya industri manufaktur belum sepenuhnya pulih ketika krisis finansial global kembali menerpa sektor ini. Hal ini disebabkan karena melemahnya pasar ekspor sehingga tahun 2009 akan menjadi tahun yang berat bagi sektor industri manufaktur.

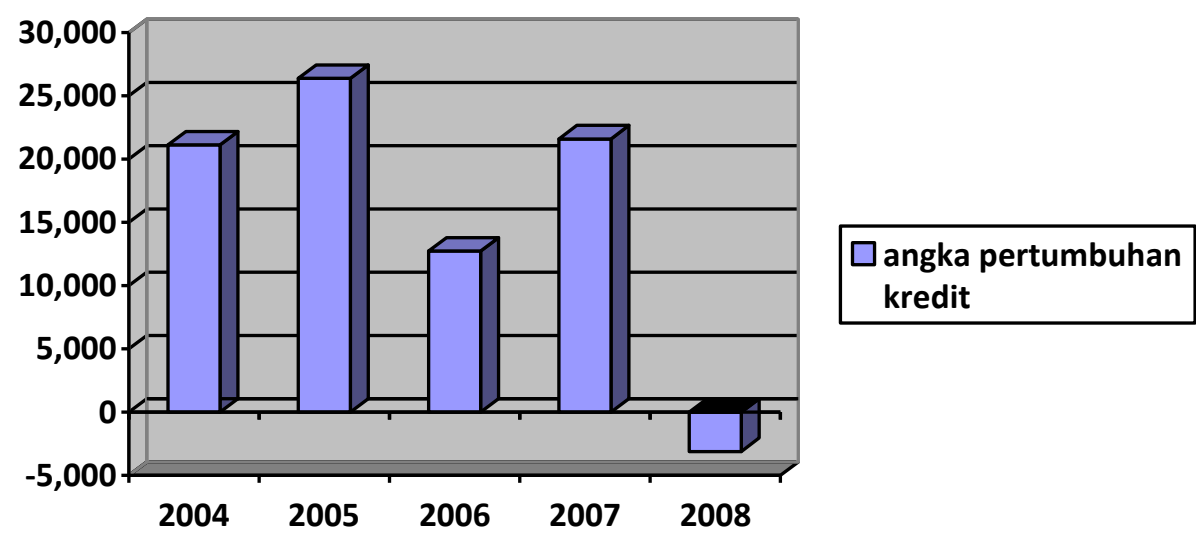

Gambar 1. Perkembangan Kredit Perbankan pada Industri Manufaktur (Rupiah)

Sumber : Statistik Perbankan Indonesia (data diolah) 


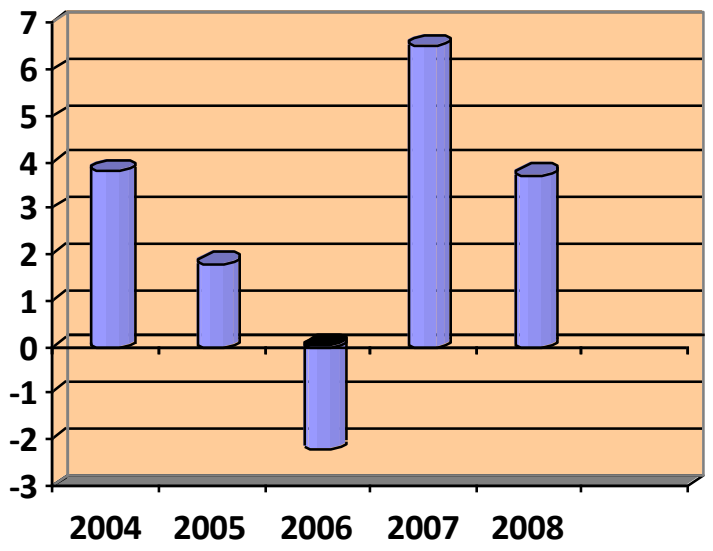

Gambar 2. Pertumbuhan Industri Manufaktur (\%)

Sumber : BPS (data diolah)
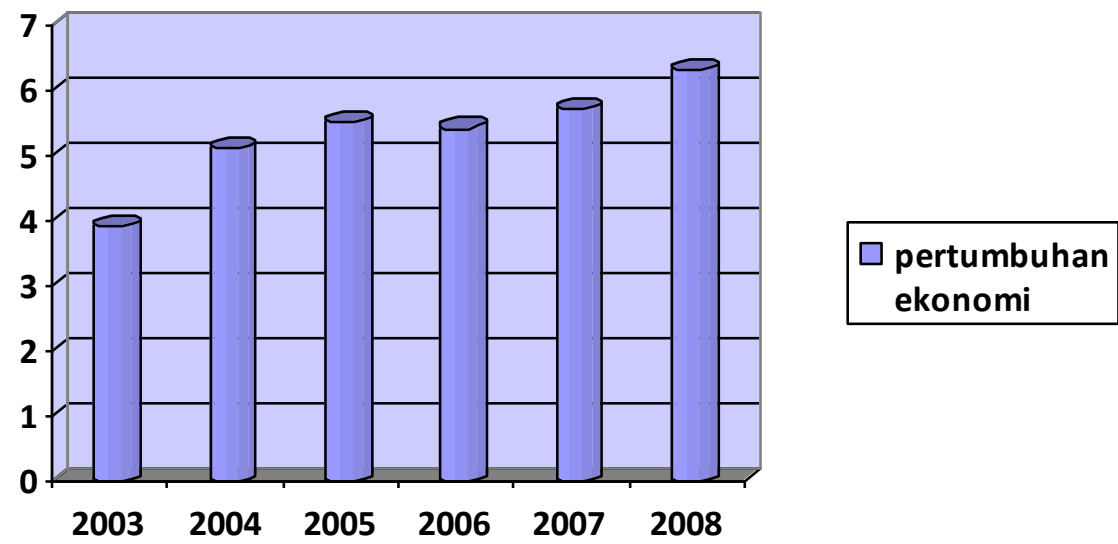

ekonomi

Gambar 3. Perkembangan Pertumbuhan Ekonomi (\%)

Sumber : BI (data diolah)

Pertumbuhan ekonomi (Gambar 3) digunakan untuk menggambarkan terjadinya kemajuan atau perkembangan ekonomi dalam suatu Negara berdasarkan periode waktu yang telah ditentukan. Suatu Negara kadang mengalami pertumbuhan ekonomi yang lambat dan juga kadang mengalami pertumbuhan ekonomi yang pesat.

Berdasarkan gambar 3 memperlihatkan bahwa pada tahun 2003 pertumbuhan ekonomi rendah dengan rata-rata sebesar 3,9\% kemudian pada tahun 2004 dan 2005 mengalami peningkatan rata-rata sebesar $5,1 \%$ dan
$5,5 \%$. Sehingga angka pertumbuhan ekonomi pada tahun 2004 sebesar 1,2\%. Namun pada tahun 2006 pertumbuhan ekonomi mengalami sedikit penurunan rata-rata sebesar 5,4\% hingga akhirnya pada tahun 2007 dan 2008 mengalami peningkatan kembali sebesar $5,7 \%$ dan $6,3 \%$. Penyebab terjadinya peningkatan ini karena faktor ketidaksamaan pemberian dana persektor pada pemerintah.

Adapun pengaruh kredit perbankan terhadap pertumbuhan industri manufaktur tahun 2003 - 2008 dapat dilihat pada persamaan berikut:

$$
\mathrm{Y}=1,175+0,173 \mathrm{X}+0,055
$$


Dari hasil perhitungan regresi diatas diperoleh koefesien determinasi $\left(\mathrm{R}^{2}\right)$ sebesar 0,713 atau $71,3 \%$ yang menunjukkan adanya kontribusi variabel Kredit perbankan terhadap pertumbuhan ekonomi sebesar 71,3 \% sedangkan sisanya $28,7 \%$ merupakan faktor yang tidak dijelaskan oleh persamaan regresi tersebut. besarnya $\mathrm{F}_{\text {hitung }}=9,920$ dengan $\alpha=0,05(5 \%)$ diperoleh $\mathrm{F}_{\text {tabel }}=4,53$. Jadi $\mathrm{F}_{\text {hitung }}>\mathrm{F}_{\text {tabel }}$ sehingga Ho ditolak dan Hi diterima, berarti kredit perbankan secara serentak berpengaruh signifikan terhadap pertumbuhan industri manufaktur.

Dari hasil $t_{\text {hitung }}$ dan $t_{\text {tabel }}$ dengan $\alpha$ $=0,05$ adalah sebagai berikut: Kredit Perbankan $(\mathrm{X}) \mathrm{t}_{\text {hitung }}=3,150$ sedangkan $\mathrm{t}_{\text {tabel }}=2,132$, maka $\mathrm{t}_{\text {hitung }}>\mathrm{t}_{\text {tabel }}$ yakni $3,150>2,132$ artinya ada pengaruh secara parsial antara variabel kredit perbankan terhadap variabel pertumbuhan industri manufaktur (Signifikan).

Adapun pengaruh pertumbuhan industri manufaktur terhadap pertumbuhan ekonomi tahun 2003 2008 dapat dilihat pada persamaan berikut:

$$
\mathrm{Y}_{2}=-6,497+3,475 \mathrm{Z}+0,0386
$$

Dari hasil perhitungan regresi diatas diperoleh koefesien determinasi $\left(\mathrm{R}^{2}\right)$ sebesar 0,760 atau $76,0 \%$ sedangkan sisanya $24,0 \%$ merupakan faktor yang tidak dijelaskan oleh persamaan regresi tersebut.

Berdasarkan hasil regresi besarnya $\mathrm{F}_{\text {hitung }}=12,679$ dengan $\alpha=0,05(5 \%)$ diperoleh $F_{\text {tabel }}=4,53$. Jadi $F_{\text {hitung }}>F_{\text {tabel }}$ dan hasil $t_{\text {hitung }}$ dan $t_{\text {tabel }}$ dengan $\alpha=0,05$ adalah sebagai berikut: pertumbuhan industri manufaktur $(\mathrm{Z}) \mathrm{t}_{\text {hitung }}=3,561$ sedangkan $t_{\text {tabel }}=2,132$, maka $t_{\text {hitung }}>$ $\mathrm{t}_{\text {tabel }}$ yakni 3,561>2,132 artinya ada pengaruh secara parsial antara variabel pertumbuhan industri manufaktur terhadap pertumbuhan ekonomi (Signifikan).
Adapun pengaruh kredit perbankan terhadap pertumbuhan ekonomi pada tahun 2003 - 2008 dapat dilihat pada persamaan berikut:

$$
\mathrm{Y}_{2}=-3,195+0,749 \mathrm{X}+0,161
$$

Berdasarkan hasil regresi besarnya $\mathrm{F}_{\text {hitung }}=21,771$ dengan $\alpha=0,05(5 \%)$ diperoleh $F_{\text {tabel }}=4,53$. Jadi $F_{\text {hitung }}>F_{\text {tabel }}$ sehingga Ho ditolak dan $\mathrm{Hi}$ diterima, berarti kredit perbankan secara serentak berpengaruh signifikan terhadap pertumbuhan ekonomi.

Dari hasil $t_{\text {hitung }}$ dan $t_{\text {tabel }}$ dengan $\alpha$ $=0,05$ adalah sebagai berikut: Kredit perbankan $(X) t_{\text {hitung }}=4,666$ sedangkan $\mathrm{t}_{\text {tabel }}=2,132$, maka $\mathrm{t}_{\text {hitung }}>\mathrm{t}_{\text {tabel }}$ yakni $3,561>2,132$ artinya ada pengaruh secara parsial

\section{PENUTUP}

Dari hasil penelitian yang telah dilakukan, maka ada beberapa hal yang harus disimpulkan, antara lain: Pertama, kredit perbankan berdampak signifikan terhadap pertumbuhan industri manufaktur. Hasilnya menunjukkan signifikasi antara kredit dengan pertumbuhan industri manufaktur. Koefesien regresi Kredit Perbankan sebesar 0,173. Dari hasiluji statistik $t_{\text {hitung }}$ dan $t_{\text {tabel }}$ dengan $\alpha=0,05$ adalah sebagai berikut : Kredit Perbankan (X) $\mathrm{t}_{\text {hitung }}=$ 3,150 sedangkan $t_{\text {tabel }}=2,132$, maka $t_{\text {hitung }}>t_{\text {tabel }}$ yakni 3,150 $>2,132$ artinya ada pengaruh signifikan antara variabel kredit perbankan terhadap variabel pertumbuhan industri manufaktur.

Kedua, Pertumbuhan industri manufaktur berdampak signifikan terhadap pertumbuhan ekonomi. hasilnya menunjukkan pengaruh signifikasi antara pertumbuhan industri manufaktur terhadap pertumbuhan ekonomi. Koefesien regresi pertumbuhan industri manufaktur sebesar 0,922. Dari hasil uji statistik $t_{\text {hitung }}$ dan $t_{\text {tabel }}$ dengan $\alpha=0,05$ adalah sebagai berikut: pertumbuhan industri 
manufaktur $(\mathrm{Z}) \mathrm{t}_{\text {hitung }}=3,561$ sedangkan $\mathrm{t}_{\text {tabel }}=2,132$, maka $\mathrm{t}_{\text {hitung }}>\mathrm{t}_{\text {tabel }}$ yakni $3,561>2,132$ artinya ada pengaruh signifikan antara variabel pertumbuhan industri manufaktur terhadap pertumbuhan ekonomi.

Ketiga, Kredit perbankan berdampak signifikan terhadap pertumbuhan ekonomi. hasilnya menunjukkan pengaruh signifikasi antara kredit dengan pertumbuhan ekonomi. Koefesien regresi Kredit Perbankan sebesar 0,749. Dari hasil $t_{\text {hitung }}$ dan $t_{\text {tabel }}$ dengan $\alpha=0,05$ adalah sebagai berikut: kredit perbankan $(\mathrm{X}) \mathrm{t}_{\text {hitung }}=4,666$ sedangkan $t_{\text {tabel }}=2,132$, maka $t_{\text {hitung }}>$ $t_{\text {tabel }}$ yakni 3,561 > 2,132 artinya ada pengaruh signifikan antara variabel kredit perbankan terhadap variabel pertumbuhan ekonomi.

Adapun saran dari peneliti yaitu, dalam mendukung perkembangan industri manufaktur dan ekonomi secara menyeluruh, hendaknya bank-bank umum lebih mengoptimalkan pemberian kredit. Karena dengan adanya kredit, industri manufaktur dapat mengembangkan usahanya dan juga berpengaruh pada perkembangan ekonomi di indonesia.

Bagi para pengusaha industri manufaktur, hendaknya tidak ceroboh dalam penggunaan kredit. Sehingga mereka dapat memanfaatkan kredit yang mereka pinjam secara optimal dan dapat meningkatkan usahanya di bidang industri manufaktur.

\section{DAFTAR PUSTAKA}

Abdullah, Faisal. 2003. Manajemen Perbankan, Malang : Umm Press.

Boediono. 1988. Teori Pertumbuhan Ekonomi. Yogyakarta : BPFE.
Kasmir. 2000. Bank dan Lembaga Keuangan Lainnya. Jakarta: PT. Raja Grafindo Persada Edisi Revisi cet. 4

Kasmir. 2004. Dasar-dasar Perbankan. Jakarta : PT. Raja Grafindo Persada. Edisi 1 cetakan 3

Lains, Alfian. 2003. Ekonometrika Teori dan Aplikasi, Jakarta : LP3ES

Mahyudi, Ahmad. 2004. Ekonomi Pembangunan dan Analisis Data Empiris. Ghalid indo.

Sanusi, Anwar. 2003. Metodologi Penelitian Praktis, Malang : Buntara Media.

Subagyo. 1999. Bank dan Lembaga Keuangan Lain. STIE YKPN.

Suhardjono. 2003. Manajemen perkreditan Usaha kecil dan menengah. jogyakarta : Unit penerbit dan percetakan (UPP) AMP YKPN.

Sutojo, Siswanto. 1995. Analisa kredit Bank Umum, jakarta : Pustaka Binaman Pressindo.

Suyatno, Thomas,dkk . $1992 \quad x r$ dasar Perkreditan edis ga. jakarta : PT. Gramedia r usıdka Utama.

Triandaru, Sigit, dkk. 2000. Bank dan lembaga Keuangan Lain. Salemba empat. 